\title{
土壤增温、氮添加及其交互作用对杉木幼苗细根生 产的影响
}

史顺增 熊德成 仍飞正建新 许辰森 钟波元 陈云玉
杨玉陈光水*

福建师范大学地理科学学院, 湿润亚热带山地生态国家重点实验室培育基地, 福州 350007

摘 要 为了揭示杉木(Cunninghamia lanceolata)人工林地下部分对全球变暖和氮沉降的响应, 在福建省三明市开展了杉木 幼苗土壤增温和氮添加双因子试验, 包括对照、增温、低氮、高氮、增温低氮、增温高氮6个处理, 用微根管法探讨试验第1 年土壤增温、氮添加及其交互作用对杉木幼苗细根生产量(以每根管细根一年总出生数量作为表征)的影响。结果表明: (1)土 壤增温对细根生产量有显著影响; 氮添加、土壤增温与氮添加交互作用对细根生产量并没有显著影响。(2)土壤增温、径级、 土壤增温和径级的交互作用对细根生产量有显著影响; 土壤增温显著增加了 0-1 mm径级细根的生产量, 表明小径级的吸收 根对于增温的响应更具有可塑性。(3)土壤增温、季节、土壤增温和季节的交互作用，以及土壤增温、氮添加和季节三者的交 互作用对细根生产量的影响均达到显著水平。春季, 土壤增温、土壤增温和氮添加的交互作用对细根生产量有显著的促进作 用; 而在夏季, 土壤增温、氮添加以及两者的交互作用对细根生产量有显著的抑制作用。(4)土壤增温、土层, 以及土壤增温 和土层的交互作用对细根生产量有显著影响, 土壤增温仅对20-30 cm土层的细根生产有显著的促进作用, 表明土壤增温促使 细根向更深层土壤分布。由此可见: 土壤增温促进了杉木幼苗细根生产, 但其影响因径级、季节和土层而异; 氮添加则对细 根生产没有影响; 土壤增温和氮添加仅在春季和夏季才存在显著的交互作用。

关键词 土壤增温; 氮添加; 杉木; 微根管; 细根生产

引用格式: 史顺增, 熊德成, 邓飞, 冯建新, 许辰森, 钟波元, 陈云玉, 陈光水, 杨玉盛 (2017). 土壤增温、氮添加及其交互作用对杉木幼苗细根生产的 影响. 植物生态学报, 41, 186-195. doi: 10.17521/cjpe.2016.0274

\section{Interactive effects of soil warming and nitrogen addition on fine root production of Chinese fir seedlings}

SHI Shun-Zeng, XIONG De-Cheng, DENG Fei, FENG Jian-Xin, XU Chen-Sen, ZHONG Bo-Yuan, CHEN Yun-Yu, CHEN Guang-Shui ${ }^{*}$, and YANG Yu-Sheng

State Key Laboratory of Humid Subtropical Mountain Ecology, School of Geographical Sciences, Fujian Normal University, Fuzhou 350007, China

\section{Abstract}

Aims There have been a large number of studies on the independent separate responses of fine roots to warming and nitrogen deposition, but with contradictory reporting. Fine root production plays a critical role in ecosystem carbon, nutrient and water cycling, yet how it responds to the interactive warming and nitrogen addition is not well understood. In the present study, we aimed to examine the interactive effects of soil warming and nitrogen addition on fine root growth of 1-year-old Chinese fir (Cunninghamia lanceolata) seedlings in subtropical China.

Methods A mesocosm experiment, with a factorial design of soil warming (ambient, $+5{ }^{\circ} \mathrm{C}$ ) and nitrogen addition (ambient, ambient $+40 \mathrm{~kg} \cdot \mathrm{hm}^{-2} \cdot \mathrm{a}^{-1}$, ambient $+80 \mathrm{~kg} \cdot \mathrm{hm}^{-2} \cdot \mathrm{a}^{-1}$ ), was carried out in the Chenda State-owned Forest Farm in Sanming City, Fujian Province, China. Fine root production (indexed by the number of fine roots emerged per tube of one year) was measured biweekly using minirhizotrons from March of 2014 to February of 2015.

Important findings (1) The two-way ANOVA showed that soil warming had a significant effect on fine root production, while nitrogen addition and soil warming $\times$ nitrogen addition had no effect. (2) The three-way ANOVA (soil warming, nitrogen addition and diameter class) showed that soil warming, diameter class and soil warming $\times$ diameter class had significant effects on fine root production, especially for the number of fine roots in

收稿日期Received: 2016-09-06 接受日期Accepted: 2016-11-10

* 通信作者Author for correspondence (E-mail: gshuichen@163.com) 
0-1 mm diameter class that had been significantly increased by soil warming. Compared with the 1-2 mm roots, the $0-1 \mathrm{~mm}$ roots seemed more flexible. (3) Repeated measures of ANOVA (soil warming, nitrogen addition and season) showed that soil warming, season, soil warming $\times$ season, and soil warming $\times$ nitrogen addition $\times$ season had significant effects on fine root production. In spring, the number of fine roots was significantly increased both by soil warming and soil warming $\times$ season, while soil warming, nitrogen addition, soil warming $\times$ nitrogen addition significantly decreased fine root production in the summer. (4) Soil warming, soil layer, soil warming $\times$ soil layer had significant effects on fine root production. The number of in-growth fine roots was significantly increased by soil warming at the 20-30 cm depth only. It seemed that warming forced fine roots to grow deeper in the soil. In conclusion, soil warming significantly increased fine root production, but they had different responses and were dependent of different diameter classes, seasons and soil layers. Nitrogen addition had no effect on fine root production. Only in spring and summer, soil warming and nitrogen addition had significant interactive effects.

Key words soil warming; nitrogen addition; Cunninghamia lanceolata; minirhizotron; fine root production

Citation: Shi SZ, Xiong DC, Deng F, Feng JX, Xu CS, Zhong BY, Chen YY, Chen GS, Yang YS (2017). Interactive effects of soil warming and nitrogen addition on fine root production of Chinese fir seedlings. Chinese Journal of Plant Ecology, 41, 186-195. doi: 10.17521/cjpe.2016.0274

据国际气候变化委员会(IPCC)第五次评估报告 预测：到21世纪末，全球地表平均增温 $0.3-4.8{ }^{\circ} \mathrm{C}$ (IPCC, 2013)。大量研究表明, 温度升高可能直接或 间接地影响森林生态系统的地上和地下生态过程 (Way \& Oren, 2010)。由于化石燃料的使用和农业施 肥的增加(Davidson, 2009), 预计到21世纪末全球氮 沉降速率将增加2-3倍(Lamarque et al., 2005)。我国 中东部森林生态系统氮沉降已超过 $20 \mathrm{~kg} \cdot \mathrm{hm}^{-2} \cdot \mathrm{a}^{-1}$, 成为全球三大氮沉降区之一, 并呈逐渐加重的趋势 (Liu et al., 2011)。因而, 研究土壤增温和氮沉降对 森林生态系统的影响对维持生态系统生产力和森林 碳汇储量等具有重要的意义。

细根(直径 $\leqslant 2 \mathrm{~mm}$ ) 是水分和养分吸收的主要器 官, 也是根系中活跃性和敏感度最高的部分 (Hendricks et al., 1993; Nadelhoffer, 2000); 同时, 细 根周转又是土壤碳输入的主要途径。目前关于增温 对不同的陆地生态系统细根生物量和生产的影响有 大量的研究, 但是并没有一致的结论。Wan等(2004) 通过空气增温的方法发现增温促进了 Acer rubrum 和A. saccharum幼苗细根的生产。Bai等(2010)对中 国北方半干旱温带草原研究发现, 增温后细根平均 年生产量降低。Wan等(2005)对高秆草(tallgrass)的研 究表明0-5、5-15和15-30 cm土层中增温与对照处理 之间细根生物量均没有显著差异。由于森林生态系 统类型、林龄和系统氮水平等因素不同, 各生态系 统细根对氮沉降的响应存在很大的不确定性, 以往 研究表明模拟氮沉降或施肥可能对森林细根生物量 有促进、抑制作用或无影响(Li et al., 2015)。Liu和 Greaver (2010)针对已发表的110篇文献进行了 meta
分析，其中涵盖10种类型的生态系统，添加氮肥的 范围为10-650 $\mathrm{kg} \cdot \mathrm{hm}^{-2} \cdot \mathrm{a}^{-1}$, 分析显示氮添加总体上 使根的生物量增加, 但对细根生产量没有影响, 仅 温带针叶林和苔原细根生产量在氮添加的情形下各 自显著地增加了 $9 \%$ 和 $74 \%$ 。Leppälammi-Kujansuu 等(2013)对挪威云杉(Picea abies, 又称欧洲云杉)的 长期增温和施肥试验表明, 土壤中出现了大量的活 根和死根, 表明细根的生产率(量)和死亡率(量)都 增加，增温、施肥及其交互作用将会显著地增加细 根生物量, 导致地下调落物生产量增加了 3-4倍。与 气候相关的环境因子都是协同作用的, 但目前有关 增温和氮沉降的交互作用对生态系统(尤其是地下 部分) 的影响的研究仍比较缺乏 (LeppälammiKujansuu et al., 2014)。

中国亚热带被称为“回归带上的绿洲”, 是全球 气候变化的敏感地带。杉木(Cunninghamia lanceolata) 是中国南方重要的造林和用材树种, 被广泛种 植, 面积达 $1239.1 \times 10^{4} \mathrm{hm}^{2}$, 蓄积量为 $47357.33 \times$ $10^{4} \mathrm{~m}^{3}$, 分别占全国人工林面积和蓄积量的 $26.55 \%$ 和 $46.89 \%$, 在中国人工林中占有重要地位(中华人 民共和国国家林业局, 2005)。为此, 本研究通过模 拟增温和氮沉降试验, 研究土壤增温和氮添加对杉 木幼苗细根生产力的影响, 以期为进一步揭示全球 环境变化下杉木人工林生产力和碳吸存的变化提供 基础数据。

\section{1 试验区概况和研究方法}

\section{1 试验区概况}

试验区位于福建三明森林生态系统与全球变化 
研究站陈大观测点 $\left(26.32^{\circ} \mathrm{N}, 117.60^{\circ} \mathrm{E}\right)$ 。平均海拔 $300 \mathrm{~m}$, 属中亚热带季风气候, 年平均气温 $19.1{ }^{\circ} \mathrm{C}$, 年降水量1 $749 \mathrm{~mm}$ (主要集中在3-8月), 年蒸发量 $1585 \mathrm{~mm}$, 相对湿度81\%。该研究区土壤以花岗岩 发育的红壤和黄壤为主。

\section{2 试验设计}

试验采用完全随机设计, 依据IPCC第五次评估 报告对21世纪末全球地表平均增温的预测(IPCC, 2013)和该研究区氮沉降背景值 $36 \mathrm{~kg} \cdot \mathrm{hm}^{-2} \cdot \mathrm{a}^{-1}$, 设置 对照(CT, 不增温、不添加额外氮素的处理), 增温 $\left(\mathrm{W},+5{ }^{\circ} \mathrm{C}\right.$, 不添加额外氮素), 低氮( $\mathrm{LN},+40 \mathrm{~kg}$. $\mathrm{hm}^{-2} \cdot \mathrm{a}^{-1}$, 指自然氮沉降背景下, 再额外添加的氮 素,下同), 高氮 $\left(\mathrm{HN},+80 \mathrm{~kg} \cdot \mathrm{hm}^{-2} \cdot \mathrm{a}^{-1}\right)$, 增温低氮 (WLN, $+5{ }^{\circ} \mathrm{C},+40 \mathrm{~kg} \cdot \mathrm{hm}^{-2} \cdot \mathrm{a}^{-1}$ ), 增温高氮(WHN, +5 $\left.{ }^{\circ} \mathrm{C},+80 \mathrm{~kg} \cdot \mathrm{hm}^{-2} \cdot \mathrm{a}^{-1}\right) 6$ 个处理, 每个处理 5 个重复, 小区面积 $2 \mathrm{~m} \times 2 \mathrm{~m}$ 。试验小区四周采用 4 块PVC板 $(200 \mathrm{~cm} \times 70 \mathrm{~cm}$ 深)焊接而成, 与周围土壤隔开, 防 止小区之间相互干扰。小区土壤取自附近的杉木林 土壤, 按0-10 cm、10-20 cm、20-70 cm分层取回, 剔 除根系、石块和其他杂物后, 分层混合均匀, 并按 20-70 cm、10-20 cm 和0-10 cm 重填回 2 m × 2 m试验 小区内, 同时采用压实法调整土壤容重与原位土壤 容重接近。于2013年10月安装加热电缆(所有小区都 布设相同电缆), 平行布设, 深度为 $10 \mathrm{~cm}$, 间距20 $\mathrm{cm}$, 并在最外围环绕一圈, 保证样地增温的均匀 性。同时在实验布设完成后在每个小区布设 4 个温度 传感器(T109, Campbell Scientific, Logan, USA)和4 个水分传感器(EC-5, Decagon, Pullman, USA), 其中 2 个温度传感器埋在 $10 \mathrm{~cm}$ 处, 另外 2 个温度传感器 分别埋在 $5 \mathrm{~cm}$ 和 $20 \mathrm{~cm}$ 深土壤中; 2 个水分传感器测 定土壤 $10 \mathrm{~cm}$ 处的含水量, 另外 2 个土壤水分传感器 监测 $5 \mathrm{~cm}$ 和 $20 \mathrm{~cm}$ 深处的土壤湿度。温度和水分传感 器均布设在两条电缆线中间位置。增温技术环节详 细描述见参考文献(陈仕东等, 2013)。2013年11月, 每个 $2 \mathrm{~m} \times 2 \mathrm{~m}$ 小区均匀种植 4 株一年生二代半短侧 枝杉木幼苗, 杉木位置均处于两条电缆线之间。在 每个小区中的2株杉木幼苗正下方布设两根微根管 用以监测杉木细根生长和死亡动态, 微根管长度 为 $90 \mathrm{~cm}$, 微根管与地面呈 $45^{\circ}$ 角插入土壤中, 换 算成垂直深度约为 $40 \mathrm{~cm}$ 。样地布设完成后, 于 2014年3月开始通电增温。并于2014年3月开始对氮 添加处理施氮肥 $\left(\mathrm{NH}_{4} \mathrm{NO}_{3}\right.$, 分析纯), 每月初以溶液
的形式对小区喷酒，全年共喷酒12次。按照处理水 平要求, 将每个小区每次所需要喷酒的 $\mathrm{NH}_{4} \mathrm{NO}_{3}$ 溶 解在 $800 \mathrm{~mL}$ (相当年降水量增加约 $2 \mathrm{~mm}$ )去离子水 中( LN 和WLN处理喷酒溶液浓度约为 $1.67 \mathrm{~g} \cdot \mathrm{L}^{-1}, \mathrm{HN}$ 和WHN处理喷酒溶液浓度约为 $3.33 \mathrm{~g} \cdot \mathrm{L}^{-1}$ ), 用手提 式喷雾器在小区四周从幼苗林冠上方对小区均匀喷 酒。其他小区喷酒等量的去离子水。同时定期清除 小区内自然萌发的其他植物。

\section{3 根系影像采集和数据采集}

从2014年3月至2015年2月对细根进行了为期 1 年的连续性观测。于每月上旬和下旬(间隔大约 15 天)使用微根管影像成像系统BTC-2 Minirhizotron Camera System (Bartz Technology, Santa Barbara, USA)对细根生长过程进行影像收集, 在 1 天内完成 每次影像的收集工作。图片收集后带回实验室用 Rootfly图像分析软件对其进行处理, 按照 $0-10 \mathrm{~cm}$ 、 10-20 cm、20-30 cm、30-40 cm进行分层处理, 并获 得每张影像中细根直径、细根长度和细根数量等数 据。同时鉴别活根和死根: 白色根、白色带红色斑 点或红色根定义为活根; 暗黑色、皮层脱落或表皮 褶皱的根定义为死根(Huang et al., 2016)。本研究中, 细根生产量用影像中每根管细根一年总出生数量作 为指标。观测期间的土壤增温和对照小区的土壤温 度和含水量变化见图1。土壤增温对不同深度土壤增 温的影响见参考文献(章宪等, 2014)。2015年1月, 采 用土钻法在每个小区随机取 4 个土样, 土钻直径 3.5 $\mathrm{cm}$, 测定 0-20 cm土壤的铵态氮和硝态氮(图2)。

\section{4 数据处理和分析}

试验观测期从2014年3月至2015年2月, 依据亚 热带气候条件, 将3-5月设为春季, 6-8月设为夏季, 9-11月设为秋季, 12月和翌年1、2月设为冬季。

采用双因素方差分析检验土壤增温、氮添加对细 根生产量的影响; 采用重复测量方差分析检验土壤增 温、氮添加、季节对细根生产量的影响; 采用三因素 方差分析检验土壤增温、氮添加、径级或土层对细根 生产量的影响。采用单因素方差分析和 $L S D$ 检验各处 理间的细根生产量差异。所有的统计分析均在SPSS 20.0 软件上进行, 显著性水平设定为 $p=0.05$ 。

\section{2 结果}

\section{1 土壤微环境}

增温对土壤温度和水分的影响均达到极显著水 

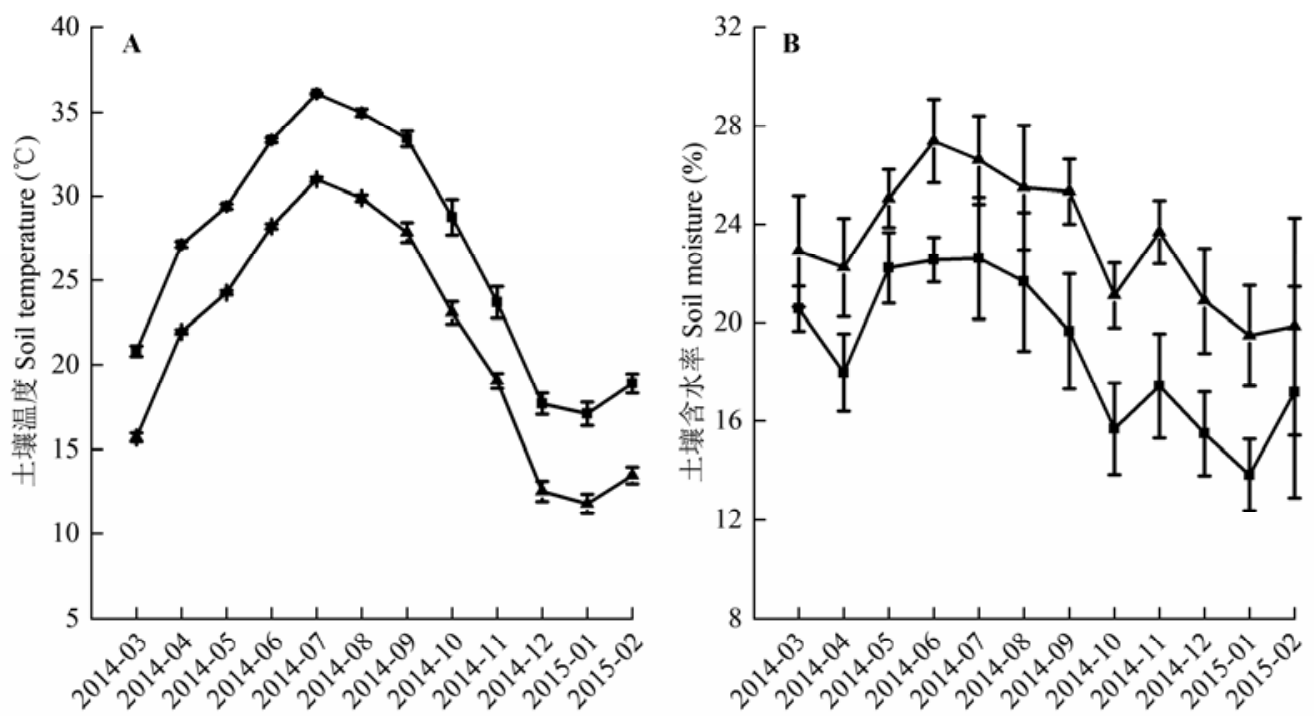

时间 Time (year-month)

图1 不同处理(以对照(不增温、不添加额外氮素的处理, $\boldsymbol{\Delta}$ )和土壤增温处理 $\left(+5{ }^{\circ} \mathrm{C}\right.$ 、不添加额外氮素的处理, $\boldsymbol{\square}$ )为例) 0-10 $\mathrm{cm}$ 土壤温度 $(\mathbf{A})$ 和含水率 $(\mathbf{B})$ 的年变化(平均值土标准偏差)。

Fig. 1 Annual changes of soil $(0-10 \mathrm{~cm})$ temperature $(\mathbf{A})$ and moisture $(\mathbf{B})$ under different treatments $($ mean $\pm S D)$. $\boldsymbol{\Delta}$, control treatment (ambient, ambient); $\mathbf{\square}$, soil warming treatment $\left(+5^{\circ} \mathrm{C}\right.$, ambient).

平 $(p<0.01)$ (表1)。与CT相比, $\mathrm{W}$ 处理土壤温度显著 增加 $(p<0.05)$ (图1A), 土壤含水率则显著下降 $(p<$ 0.05)(图1B)。增温和氮添加对铵态氮、硝态氮和土 壤有效氮的影响均达到极显著水平 $(p<0.01)$; 增温 和氮添加的交互作用对铵态氮和土壤有效氮的影响 达到极显著水平 $(p<0.01)$, 对硝态氮没有影响 $(p>$ 0.05)(表1)。处理间比较可知, WHN的铵态氮显著高 于其他处理 $(p<0.01)$, HN和WLN处理的铵态氮均 显著高于CT和LN处理 $(p<0.01)$; WHN的硝态氮和 土壤有效氮均显著高于其他处理 $(p<0.01)$, 而 $\mathrm{HN}$ 、 W 和WLN处理的硝态氮和土壤有效氮显著高于CT 和LN $(p<0.01)$ (图2)。

\section{2 细根生产量}

土壤增温对细根生产量有显著的促进作用 $(p<$ $0.05)$, 而氮添加、土壤增温和氮添加的交互作用对 细根生产量没有影响 $(p>0.05)($ 表2)。W处理的细根 生产量显著高于LN和HN处理 $(p<0.05)$; WHN处理 细根生产量显著高于HN处理 $(p<0.05)$; 其他处理 之间均无显著差异 $(p>0.05)$ (图3A)。

\section{3 细根生产量的径级分布}

土壤增温、径级、土壤增温和径级的交互作用 对细根生产量有显著影响 $(p<0.05)$, 但氮添加、土 壤增温和氮添加的交互作用、氮添加和径级的交互 作用, 以及三者的交互作用对细根生产量没有影响 $(p>0.05)$ (表3)。在0-1 mm径级中, 土壤增温对细根

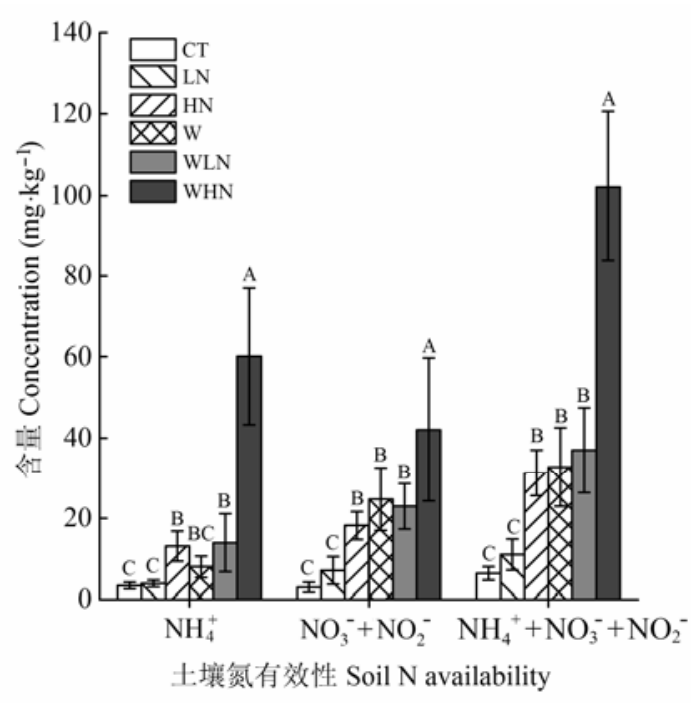

图2 不同处理0-20 cm 土壤氮有效性(平均值土标准偏差)。 $\mathrm{NH}_{4}{ }^{+}$, 铵态氮。 $\mathrm{NO}_{3}{ }^{-}+\mathrm{NO}_{2}^{-}$, 硝态氮。CT, 对照(不增温、 不添加额外氮素); $\mathrm{HN}$, 高氮(不增温, $+80 \mathrm{~kg} \cdot \mathrm{hm}^{-2} \cdot \mathrm{a}^{-1}$, 指自 然氮沉降背景下, 再额外添加的氮素量,下同); LN, 低氮(不 增温, $\left.+40 \mathrm{~kg} \cdot \mathrm{hm}^{-2} \cdot \mathrm{a}^{-1}\right)$; $\mathrm{W}$, 土壤增温 $\left(+5{ }^{\circ} \mathrm{C}\right.$, 不添加额外氮 素); WHN, 土壤增温+高氮 $\left(+5{ }^{\circ} \mathrm{C},+80 \mathrm{~kg} \cdot \mathrm{hm}^{-2} \cdot \mathrm{a}^{-1}\right)$; WLN, 土壤增温 + 低氮 $\left(+5{ }^{\circ} \mathrm{C},+40 \mathrm{~kg} \cdot \mathrm{hm}^{-2} \cdot \mathrm{a}^{-1}\right)$ 。不同大写字母表示 不同处理间差异显著 $(p<0.05)$ 。

Fig. 2 Soil $(0-20 \mathrm{~cm})$ nitrogen availability under different treatments (mean $\pm S D$ ). $\mathrm{NH}_{4}^{+}$, ammonium nitrogen. $\mathrm{NO}_{3}{ }^{-}+$ $\mathrm{NO}_{2}^{-}$, nitrate nitrogen. CT, control treatment (ambient, ambient); HN, high nitrogen addition (ambient, ambient +80 $\mathrm{kg} \cdot \mathrm{hm}^{-2} \cdot \mathrm{a}^{-1}$ ); LN, low nitrogen addition (ambient, ambient +40 $\left.\mathrm{kg} \cdot \mathrm{hm}^{-2} \cdot \mathrm{a}^{-1}\right)$; W, soil warming $\left(+5{ }^{\circ} \mathrm{C}\right.$, ambient); WHN, soil warming plus high nitrogen addition $\left(+5{ }^{\circ} \mathrm{C}\right.$, ambient +80 $\left.\mathrm{kg} \cdot \mathrm{hm}^{-2} \cdot \mathrm{a}^{-1}\right)$; WLN, soil warming plus low nitrogen addition $\left(+5{ }^{\circ} \mathrm{C}\right.$, ambient $\left.+40 \mathrm{~kg} \cdot \mathrm{hm}^{-2} \cdot \mathrm{a}^{-1}\right)$. Different capital letters indicate significant differences among treatments $(p<0.05)$. 
表1 土壤增温、氮添加及其交互作用对土壤温度、含水率和土壤有效氮影响的双因素方差分析 $p$ 值

Table $1 p$-value of two-way ANOVA on the effects of soil warming, nitrogen addition and their interaction on soil temperature, soil moisture and soil nitrogen availability

\begin{tabular}{|c|c|c|c|c|c|}
\hline $\begin{array}{l}\text { 因子 } \\
\text { Factor }\end{array}$ & $\begin{array}{l}\text { 土壤温度 } \\
\text { Soil temperature }\left({ }^{\circ} \mathrm{C}\right)\end{array}$ & $\begin{array}{l}\text { 土壤湿度 } \\
\text { Soil moisture (\%) }\end{array}$ & $\begin{array}{l}\text { 铵态氮 } \\
\text { Ammonium nitrogen }\end{array}$ & $\begin{array}{l}\text { 硝态氮 } \\
\text { Nitrate nitrogen }\end{array}$ & $\begin{array}{l}\text { 土壤有效氮(铵态氮和硝态氮) } \\
\text { Soil nitrogen availability } \\
\text { (ammonium nitrogen and nitrate nitrogen) }\end{array}$ \\
\hline W & $<0.001$ & 0.005 & $<0.001$ & $<0.001$ & $<0.001$ \\
\hline $\mathrm{N}$ & & & $<0.001$ & $<0.001$ & $<0.001$ \\
\hline $\mathrm{W} \times \mathrm{N}$ & & & $<0.001$ & 0.317 & $<0.001$ \\
\hline
\end{tabular}

$\mathrm{N}$, 氮添加; $\mathrm{W}$, 土壤增温; $\mathrm{W} \times \mathrm{N}$, 土壤增温与氮添加的交互作用。

$\mathrm{N}$, nitrogen addition; $\mathrm{W}$, soil warming; $\mathrm{W} \times \mathrm{N}$, interaction of soil warming and nitrogen addition.

表2 土壤增温、氮添加及其交互作用对每根管细根一年总出生数量影 响的双因素方差分析 $p$ 值

Table $2 p$-value of two-way ANOVA on the effects of soil warming, nitrogen addition and their interaction on total number of fine roots emerged per tube of one year

\begin{tabular}{lccc}
\hline 指标 Index & \multicolumn{3}{c}{ 因子 Factor } \\
\cline { 2 - 4 } & $\mathrm{W}$ & $\mathrm{N}$ & $\mathrm{W} \times \mathrm{N}$ \\
\hline 每根管细根一年总出生数量 & 0.005 & 0.616 & 0.483
\end{tabular}

Total number of fine roots emerged

per tube of one year $\left(\right.$ No. $\cdot$ tube $\left.^{-1} \cdot \mathrm{a}^{-1}\right)$

$\mathrm{N}$, 氮添加; $\mathrm{W}$, 土壤增温; $\mathrm{W} \times \mathrm{N}$, 土壤增温与氮添加的交互作用。

$\mathrm{N}$, nitrogen addition; $\mathrm{W}$, soil warming; $\mathrm{W} \times \mathrm{N}$, interaction of soil warming and nitrogen addition.

生产量有显著的促进作用 $(p<0.05)$ (表4); 各处理间 比较发现, W 和WHN处理细根生产量显著高于LN 和 $\mathrm{HN}$ 处理 $(p<0.05)$ (图3B); 而在1-2 mm径级中, 土壤增温、氮添加及其交互作用对细根生产量均没 有显著的影响 $(p>0.05)$ (表4); 只有WHN处理细根
生产量显著低于LN处理 $(p<0.05)$ (图3B)。在所有处 理中, 0-1 mm径级细根生产量均极显著高于 $1-2 \mathrm{~mm}$ 径级 $(p<0.01)$ (图3B)。

\section{4 细根生产量的季节动态}

土壤增温、季节、土壤增温和季节的交互作用, 以及土壤增温、氮添加和季节三者的交互作用对细 根生产量的影响均达到显著水平 $(p<0.05)$ (表5)。在 春季, 土壤增温、土壤增温和氮添加的交互作用对 细根生产量有显著的促进作用 $(p<0.05)$, 但氮添加 对细根生产量则无显著的影响 $(p>0.05)$ (表4); 处理 间比较发现: W和WHN处理细根生产量显著高于 CT和 HN处理 $(p<0.05)$ (图4); 在夏季, 土壤增温、氮 添加、土壤增温和氮添加的交互作用对细根生产量 有显著的抑制作用 $(p<0.05)$ (表4); CT处理细根生产
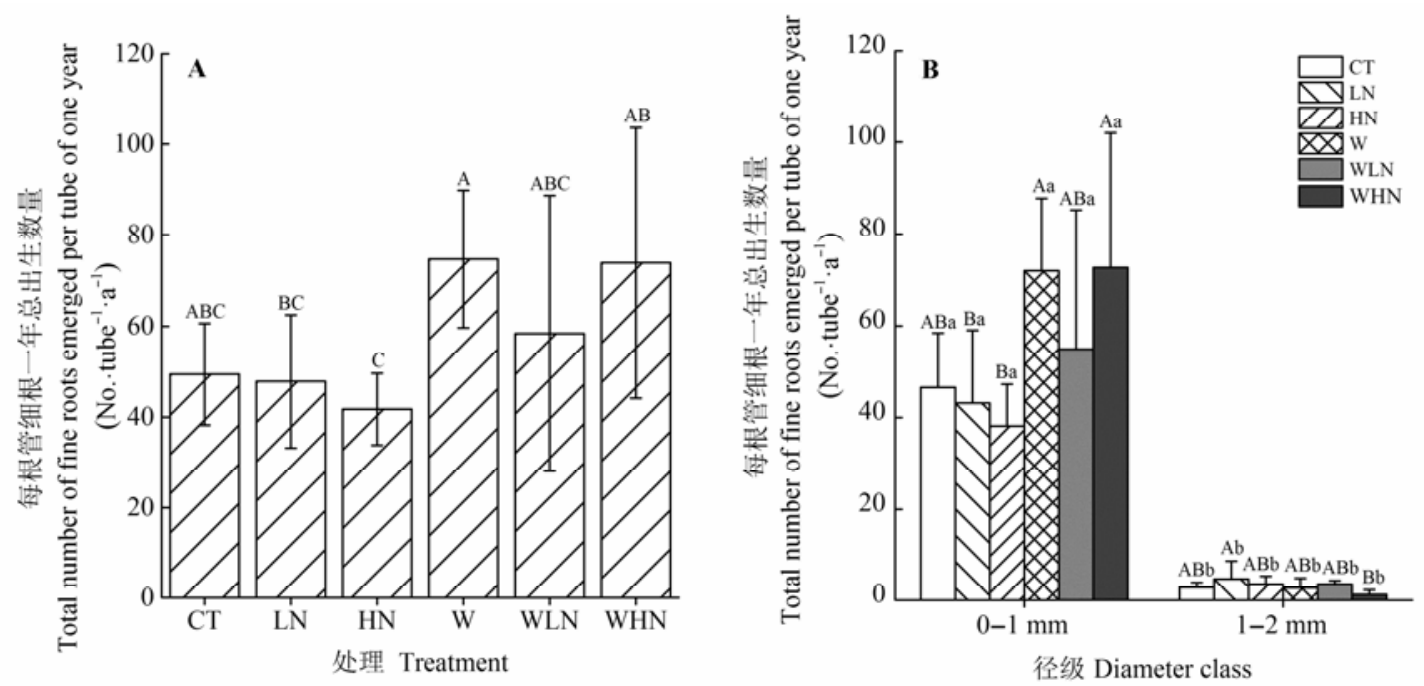

图3 不同处理每根管细根一年总出生数量(A)和细根径级分布 $(\mathbf{B})$ (平均值沶准偏差)。不同大写字母表示不同处理差异显著 $(p<0.05)$, 不同小写字母表示相同处理不同径级间差异显著 $(p<0.05)$ C CT, 对照(不增温、不添加额外氮素); HN, 高氮(不增 温, $+80 \mathrm{~kg} \cdot \mathrm{hm}^{-2} \cdot \mathrm{a}^{-1}$, 指自然氮沉降背景下, 再额外添加的氮素量,下同); LN, 低氮(不增温, $\left.+40 \mathrm{~kg} \cdot \mathrm{hm}^{-2} \cdot \mathrm{a}^{-1}\right) ; \mathrm{W}$, 土壤增温 $(+5$ ${ }^{\circ} \mathrm{C}$, 不添加额外氮素 $)$; WHN, 土壤增温 + 高氮 $\left(+5{ }^{\circ} \mathrm{C},+80 \mathrm{~kg} \cdot \mathrm{hm}^{-2} \cdot \mathrm{a}^{-1}\right)$; WLN, 土壤增温 + 低氮 $\left(+5{ }^{\circ} \mathrm{C},+40 \mathrm{~kg} \cdot \mathrm{hm}^{-2} \cdot \mathrm{a}^{-1}\right)$ 。

Fig. 3 Total number of fine roots emerged of one year (A) under different treatments and number of different diameter class (B) (mean $\pm S D$ ). Different capital letters indicate significant differences among treatments $(p<0.05)$. Different lowercase letters indicate significant differences among diameters $(p<0.05)$. CT, control treatment (ambient, ambient); HN, high nitrogen addition (ambient, ambient $+80 \mathrm{~kg} \cdot \mathrm{hm}^{-2} \cdot \mathrm{a}^{-1}$ ); LN, low nitrogen addition (ambient, ambient $+40 \mathrm{~kg} \cdot \mathrm{hm}^{-2} \cdot \mathrm{a}^{-1}$ ); W, soil warming $\left(+5^{\circ} \mathrm{C}\right.$, ambient); WHN, soil warming plus high nitrogen addition $\left(+5^{\circ} \mathrm{C}\right.$, ambient $\left.+80 \mathrm{~kg} \cdot \mathrm{hm}^{-2} \cdot \mathrm{a}^{-1}\right)$; WLN, soil warming plus low nitrogen addition $\left(+5^{\circ} \mathrm{C}\right.$, ambient $\left.+40 \mathrm{~kg} \cdot \mathrm{hm}^{-2} \cdot \mathrm{a}^{-1}\right)$. 
表3 土壤增温、氮添加和径级对每根管细根一年总出生数量影响的方差分析p值

Table $3 p$-value of ANOVA on the effects of soil warming, nitrogen addition and diameter class on total number of fine roots emerged per tube of one year

\begin{tabular}{|c|c|c|c|c|c|c|c|}
\hline \multirow[t]{2}{*}{ 指标 Index } & & \multicolumn{6}{|c|}{ 因子 Factor } \\
\hline & & $\overline{\mathrm{W}}$ & $\mathrm{D}$ & $\mathrm{W} \times \mathrm{N}$ & $\mathrm{W} \times \mathrm{D}$ & $\mathrm{N} \times \mathrm{D}$ & $\overline{W \times N \times D}$ \\
\hline \multicolumn{2}{|c|}{$\begin{array}{l}\text { 每根管细根一年总出生数量 } \\
\text { Total number of fine roots emerged per tube of one year }\left(\text { No. } \cdot \text { tube }{ }^{-1} \cdot \mathrm{a}^{-1}\right)\end{array}$} & 0.624 & $<0.001$ & 0.491 & 0.002 & 0.44 & 0.431 \\
\hline \multicolumn{8}{|c|}{$\begin{array}{l}\mathrm{D} \text {, 径级; } \mathrm{N} \text {, 氮添加; } \mathrm{N} \times \mathrm{D} \text {, 氮添加与径级的交互作用; } \mathrm{W} \text {, 土壤增温; } \mathrm{W} \times \mathrm{D} \text {, 土壤增温与径级的交互作用; } \mathrm{W} \times \mathrm{N} \text {, 土壤增温与氮添加的交互作用; } \mathrm{W} \\
\times \mathrm{N} \times \mathrm{V} \text { 添加和径级三者的交互作用。 } \\
\mathrm{D} \text {, diameter class; } \mathrm{N} \text {, nitrogen addition; } \times \mathrm{D} \text {, interaction of nitrogen addition and diameter class; } \mathrm{W} \text {, soil warming; } \mathrm{W} \times \mathrm{D} \text {, interaction of soil warming and } \\
\text { diameter class; } \mathrm{W} \times \mathrm{N} \text {, interaction of soil warming and nitrogen addition; } \mathrm{W} \times \mathrm{N} \times \mathrm{D} \text {, interaction of soil warming, nitrogen addition and diameter class. }\end{array}$} \\
\hline \multicolumn{8}{|c|}{$\begin{array}{l}\text { 表4 不同径级、不同季节、不同土层中的土壤增温、氮添加及其交互作用对每根管细根一年总出生数量影响的双因素方差分析 } p \text { 值 } \\
\text { Table } 4 \text { p-value of two-way ANOVA on the effects of soil warming, nitrogen addition and their interaction on total number of fine roots emerged per tube of } \\
\text { one year in different diameter classes, seasons and soil layers }\end{array}$} \\
\hline 指标 Index & \multicolumn{2}{|c|}{ 因子 Factor } & & $\mathrm{W}$ & \multicolumn{2}{|c|}{$\mathrm{N}$} & $\mathrm{W} \times \mathrm{N}$ \\
\hline \multirow{10}{*}{$\begin{array}{l}\text { 每根管细根一年总出生数量 } \\
\text { Total mumber of fine roots emerged per tube of } \\
\text { one year }\left(\text { No. } \cdot \text { tube }{ }^{-1} \cdot \mathrm{a}^{-1} \text { ) }\right.\end{array}$} & \multirow{2}{*}{$\begin{array}{l}\text { 径级 } \\
\text { Diameter class }\end{array}$} & $0-1 \mathrm{~mm}$ & & 0.004 & \multicolumn{2}{|c|}{0.535} & 0.465 \\
\hline & & $1-2 \mathrm{~mm}$ & & 0.137 & \multicolumn{2}{|l|}{0.182} & 0.505 \\
\hline & \multirow{4}{*}{$\begin{array}{l}\text { 季节 } \\
\text { Season }\end{array}$} & 春季 Spring & & $<0.001$ & \multicolumn{2}{|c|}{0.529} & 0.010 \\
\hline & & 夏季 Summer & & 0.003 & \multicolumn{2}{|c|}{0.001} & 0.041 \\
\hline & & 秋季 Autumn & & 0.226 & \multicolumn{2}{|l|}{0.555} & 0.971 \\
\hline & & 冬季 Winter & & 0.702 & \multicolumn{2}{|c|}{0.175} & 0.313 \\
\hline & \multirow{4}{*}{$\begin{array}{l}\text { 土层 } \\
\text { Soil layer }\end{array}$} & $0-10 \mathrm{~cm}$ & & 0.547 & \multicolumn{2}{|l|}{0.488} & 0.423 \\
\hline & & $10-20 \mathrm{~cm}$ & & 0.158 & \multicolumn{2}{|c|}{0.114} & 0.052 \\
\hline & & $20-30 \mathrm{~cm}$ & & 0.005 & \multicolumn{2}{|c|}{0.424} & 0.892 \\
\hline & & $30-40 \mathrm{~cm}$ & & 0.124 & \multicolumn{2}{|c|}{0.379} & 0.892 \\
\hline
\end{tabular}

$\mathrm{W}$, 土壤增温; $\mathrm{N}$, 氮添加; $\mathrm{W} \times \mathrm{N}$, 土壤增温与氮添加的交互作用。

$\mathrm{W}$, soil warming; $\mathrm{N}$, nitrogen addition; $\mathrm{W} \times \mathrm{N}$, interaction of soil warming and nitrogen addition.

表5土壤增温、氮添加和季节对每根管细根一年总出生数量影响的重复测量方差分析的 $p$ 值

Table 5 -value of repeated measures ANOVA on the effects of soil warming, nitrogen addition and season on total number of fine roots emerged per tube of one year

\begin{tabular}{llllllll}
\hline 指标 Index & \multicolumn{7}{c}{ 因子 Factor } \\
\cline { 2 - 8 } & $\mathrm{W}$ & $\mathrm{N}$ & $\mathrm{S}$ & $\mathrm{W} \times \mathrm{N}$ & $\mathrm{W} \times \mathrm{S}$ & $\mathrm{N} \times \mathrm{S}$ & $\mathrm{W} \times \mathrm{N} \times \mathrm{S}$ \\
\hline $\begin{array}{l}\text { 每根管细根一年总出生数量 } \\
\text { Total number of fine roots emerged per tube of one year }\left(\mathrm{No} \cdot \mathrm{tube}^{-1} \cdot \mathrm{a}^{-1} \text { ) }\right.\end{array}$ & 0.005 & 0.616 & $<0.001$ & 0.483 & $<0.001$ & 0.193 & 0.025 \\
\hline $\mathrm{N}$
\end{tabular}

$\mathrm{N}$, 氮添加; $\mathrm{S}$, 季节; $\mathrm{N} \times \mathrm{S}$, 氮添加与季节的交互作用; $\mathrm{W}$, 土壤增温; $\mathrm{W} \times \mathrm{N}$, 土壤增温与氮添加的交互作用; $\mathrm{W} \times \mathrm{S}$, 土壤增温与季节的交互作用; $\mathrm{W} \times$ $\mathrm{N} \times \mathrm{S}$, 土壤增温、氮添加和季节三者的交互作用。

$\mathrm{N}$, nitrogen addition; S, season; $\mathrm{N} \times \mathrm{S}$, interaction of nitrogen addition and season; $\mathrm{W}$, soil warming; $\mathrm{W} \times \mathrm{N}$, interaction of soil warming and nitrogen addition; $\mathrm{W} \times \mathrm{S}$, interaction of soil warming and season; $\mathrm{W} \times \mathrm{N} \times \mathrm{S}$, interaction of soil warming, nitrogen addition and season.

量显著高于其他处理 $(p<0.05), W 、 L N 、 W L N 、 H N$ 和WLN处理间均无显著差异 $(p>0.05)$; 在秋季, 土 壤增温、氮添加、土壤增温和氮添加的交互作用对 细根生产量均无显著影响 $(p>0.05)$; 不同处理间也 没有显著差异 $(p>0.05)$ (表4); 在冬季, 土壤增温、 氮添加、土壤增温和氮添加的交互作用对细根生产 量均无显著影响 $(p>0.05)$ (表4); 只有WLN处理细 根生产量显著高于W处理。不同处理细根出生的季 节模式不同, CT处理夏季细根生产量显著高于春、 秋、冬季 $(p<0.05)$; $\mathrm{W}$ 和LN处理春季细根生产量显 著高于其他季节 $(p<0.05)$; WLN和WHN处理春秋 季细根生产量高于夏季和冬季; HN处理四个季节之 间细根生产量没有显著差异 $(p>0.05)$, 但在秋季最 高(图4)。

\section{5 细根生产量的垂直分布}

土壤增温、土层以及土壤增温和土层的交互作 用对细根生产量有显著影响 $(p<0.01)$ (表6)。在0-10 $\mathrm{cm}$ 土层, 土壤增温、氮添加、土壤增温和氮添加的 交互作用对细根生产量均无显著影响 $(p>0.05)$ (表 $4)$; 不同处理间细根生产量也没有差异 $(p>0.05)$ (图 5)。在10-20 cm土层, 土壤增温、氮添加、土壤增温 和氮添加的交互作用对细根生产量均无显著影响 $(p>0.05)$ (表4); 处理间比较, W和WHN处理细根生 产量显著高于WLN和HN处理 $(p<0.05)$ (图5)。在 20-30 cm土层, 土壤增温对细根生产量有显著的促 进作用 $(p<0.05)$, 但氮添加、土壤增温和氮添加的 交互作用对细根生产量无显著影响 $(p>0.05)$ (表4); W和WHN处理细根生产量显著高于LN和HN处理 


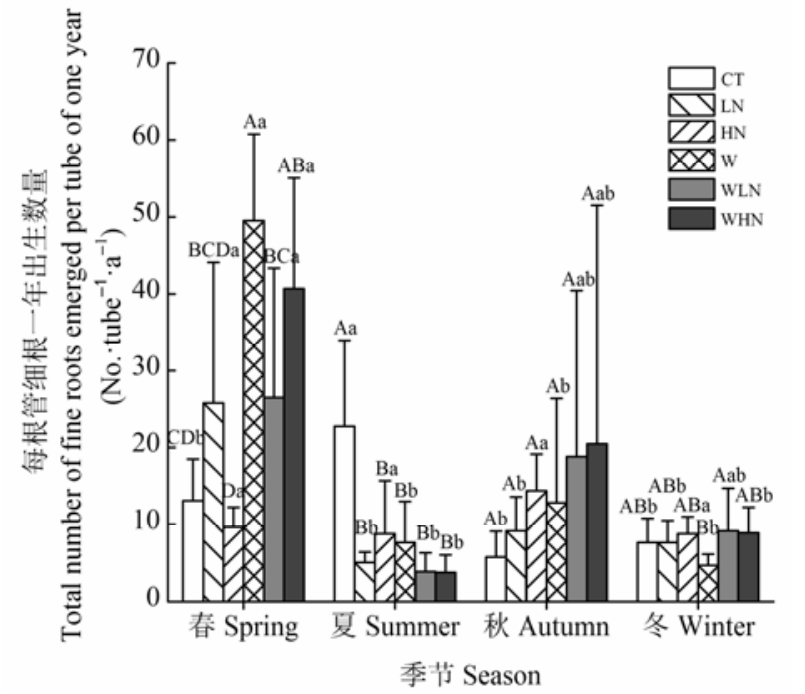

图4 不同季节每根管细根一年总出生数量(平均值土标准偏 差)。不同大写字母表示相同季节不同处理间差异显著 $(p<$ $0.05)$, 不同小写字母表示相同处理不同季节间差异显著 $(p<$ 0.05)。CT, 对照 (不增温、不添加额外氮素); HN, 高氮(不 增温, $+80 \mathrm{~kg} \cdot \mathrm{hm}^{-2} \cdot \mathrm{a}^{-1}$, 指自然氮沉降背景下, 再额外添加的 氮素量,下同); LN, 低氮(不增温, $+40 \mathrm{~kg} \cdot \mathrm{hm}^{-2} \cdot \mathrm{a}^{-1}$ ); W, 土壤 增温 $\left(+5{ }^{\circ} \mathrm{C}\right.$, 不添加额外氮素); WHN, 土壤增温+高氮 $(+5$ $\left.{ }^{\circ} \mathrm{C},+80 \mathrm{~kg} \cdot \mathrm{hm}^{-2} \cdot \mathrm{a}^{-1}\right) ; \mathrm{WLN}$, 土壤增温 + 低氮 $\left(+5{ }^{\circ} \mathrm{C},+40\right.$ $\left.\mathrm{kg} \cdot \mathrm{hm}^{-2} \cdot \mathrm{a}^{-1}\right)$ 。

Fig. 4 Total number of fine roots emerged per tube of one year under different seasons (mean $\pm S D$ ). Different capital letters indicate significant differences among treatments in the same season $(p<0.05)$. Different lowercase letters indicate significant differences among seasons in the same treatment $(p<0.05)$. CT, control treatment (ambient, ambient); HN, high nitrogen addition (ambient, ambient $+80 \mathrm{~kg} \cdot \mathrm{hm}^{-2} \cdot \mathrm{a}^{-1}$ ); LN, low nitrogen addition (ambient, ambient $+40 \mathrm{~kg} \cdot \mathrm{hm}^{-2} \cdot \mathrm{a}^{-1}$ ); $\mathrm{W}$, soil warming $\left(+5{ }^{\circ} \mathrm{C}\right.$, ambient); WHN, soil warming plus high nitrogen addition $\left(+5^{\circ} \mathrm{C}\right.$, ambient $\left.+80 \mathrm{~kg} \cdot \mathrm{hm}^{-2} \cdot \mathrm{a}^{-1}\right)$; WLN, soil warming plus low nitrogen addition $\left(+5{ }^{\circ} \mathrm{C}\right.$, ambient +40 $\mathrm{kg} \cdot \mathrm{hm}^{-2} \cdot \mathrm{a}^{-1}$ ).

$(p<0.05)$ (图5); 在30-40 cm土层, 土壤增温、氮添 加、土壤增温和氮添加的交互作用对细根生产量均 无显著影响 $(p>0.05)($ 表 4$)$; 不同处理间细根生产量 没有差异 $(p>0.05)$ (图5)。

\section{3 讨论}

\section{1 土壤增温和氮添加对杉木幼苗细根生产的影 响机制}

增温能促进土壤温度升高, 提高土壤氮有效性, 同时也会降低土壤水分有效性，进而促进细根生 产。氮添加虽然会提高土壤氮有效性, 但对细根生 产没有显著影响。从总体上看, 土壤增温和氮添加 对细根生产并没有显著的交互作用(图6)。

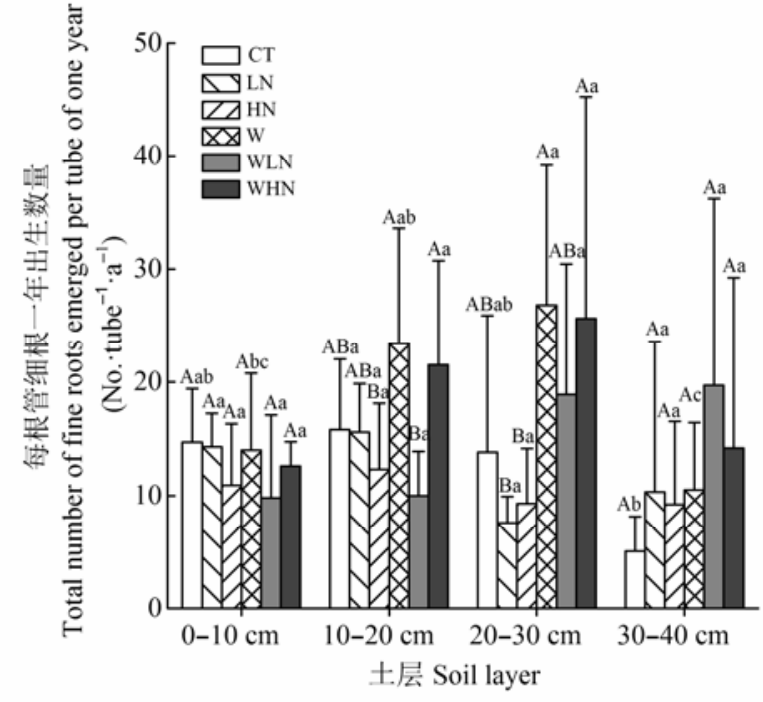

图5 不同土层每根管细根一年总出生数量(平均值土标准偏 差)。不同大写字母表示相同土层不同处理间差异显著 $(p<$ $0.05)$; 不同小写字母表示相同处理不同土层间差异显著 $(p<$ 0.05 )。CT, 对照(不增温、不添加额外氮素); HN, 高氮(不增 温, $+80 \mathrm{~kg} \cdot \mathrm{hm}^{-2} \cdot \mathrm{a}^{-1}$, 指自然氮沉降背景下, 再额外添加的氮 素量,下同); $\mathrm{LN}$, 低氮(不增温, $+40 \mathrm{~kg} \cdot \mathrm{hm}^{-2} \cdot \mathrm{a}^{-1}$ ); $\mathrm{W}$, 土壤增 温 $\left(+5{ }^{\circ} \mathrm{C}\right.$, 不添加额外氮素 $) ; \mathrm{WHN}$, 土壤增温 + 高氮 $\left(+5{ }^{\circ} \mathrm{C}\right.$, $\left.+80 \mathrm{~kg} \cdot \mathrm{hm}^{-2} \cdot \mathrm{a}^{-1}\right)$; WLN, 土壤增温 + 低氮 $\left(+5{ }^{\circ} \mathrm{C},+40\right.$ $\left.\mathrm{kg} \cdot \mathrm{hm}^{-2} \cdot \mathrm{a}^{-1}\right)$ 。

Fig. 5 Total number of fine roots emerged per tube of one year under different soil layer (mean $\pm S D$ ). Different capital letters indicate significant differences among treatments in the same soil layer $(p<0.05)$. Different lowercase letters indicate significant differences among soil layers in the same treatment $(p<0.05)$. CT, control treatment (ambient, ambient); HN, high nitrogen addition (ambient, ambient $+80 \mathrm{~kg} \cdot \mathrm{hm}^{-2} \cdot \mathrm{a}^{-1}$ ); LN, low nitrogen addition (ambient, ambient $+40 \mathrm{~kg} \cdot \mathrm{hm}^{-2} \cdot \mathrm{a}^{-1}$ ); W, soil warming $\left(+5{ }^{\circ} \mathrm{C}\right.$, ambient); WHN, soil warming plus high nitrogen addition $\left(+5^{\circ} \mathrm{C}\right.$, ambient $\left.+80 \mathrm{~kg} \cdot \mathrm{hm}^{-2} \cdot \mathrm{a}^{-1}\right)$; WLN, soil warming plus low nitrogen addition $\left(+5{ }^{\circ} \mathrm{C}\right.$, ambient +40 $\left.\mathrm{kg} \cdot \mathrm{hm}^{-2} \cdot \mathrm{a}^{-1}\right)$.

\section{2 细根生产量}

本研究中, 土壤增温对细根生产量有显著的促 进作用，尤其是 $\mathrm{W}$ 处理细根生产量显著高于 $\mathrm{LN}$ 和 HN处理, WHN处理细根生产量显著高于HN处理。 Majdj和Öhrvik (2004)对瑞典北部的挪威云杉进行 增温和施肥交互试验发现，增温样地和增温+施肥 样地的细根生产量显著高于对照样地和施肥样地, 主要原因是土壤增温促进了土壤矿化速率，提高了 养分有效性, 从而使细根生产量增加(Fitter et al., 1999; Wan et al., 2004)。此外, 增温对细根生产量有 显著促进作用, 也有可能要归因于增温会延长细根 的生长季节(Majdi \& Öhrvik, 2004)。LeppälammiKujansuu等(2013)对挪威云杉的长期增温和施肥试 
表6 土壤增温、氮添加和土层对每根管细根一年总出生数量影响的方差分析 $p$ 值

Table $6 \quad p$-value of ANOVA on the effects of soil warming, nitrogen addition and soil layer on total number of fine roots emerged per tube of one year

\begin{tabular}{|c|c|c|c|c|c|c|c|}
\hline \multirow[t]{2}{*}{ 指标 Index } & \multicolumn{7}{|c|}{ 因子 Factor } \\
\hline & $\mathrm{W}$ & $\mathrm{N}$ & $\mathrm{L}$ & $\mathrm{W} \times \mathrm{N}$ & $\mathrm{W} \times \mathrm{L}$ & $\mathrm{N} \times \mathrm{L}$ & $\mathrm{W} \times \mathrm{N} \times \mathrm{L}$ \\
\hline $\begin{array}{l}\text { 每根管细根一年总出生数量 } \\
\text { Total number of fine roots emerged per tube of one year }\left(\text { No. }^{\prime} \cdot \text { tube }^{-1} \cdot \mathrm{a}^{-1}\right)\end{array}$ & 0.001 & 0.563 & 0.06 & 0.419 & 0.025 & 0.256 & 0.765 \\
\hline
\end{tabular}

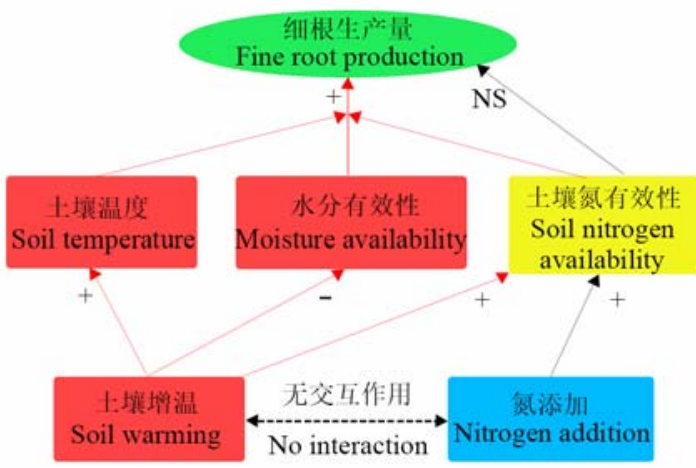

图6 土壤增温和氮添加对杉木幼苗细根生产的影响机制。 “+”表示促进; “-”表示抑制; “NS”表示无显著影响。红色箭头 表示受土壤增温的影响; 黑色箭头表示受氮添加的影响。

Fig. 6 Proposed mechanism on the effects of soil warming and nitrogen addition on fine root production. "+" means increase; "-" means decrease; "NS" means have no significant effect. The red arrows mean effects by soil warming; while the black arrows mean effects by nitrogen addition.

验结果表明, 土壤增温后生长季节延长且土壤中氮 有效性增加, 从而促进了细根的生产量增加。另有 研究表明: 在降水量或者水分有效性丰富的地带, 增温会导致细根生产量和死亡量提高(Fitter et al., 1999; Wan et al., 2004)。而在水分受限制的生态系 统, 如温带半干旱草原, 增温会显著降低细根生产 量(Bai et al., 2010)。该研究区地处亚热带, 降水丰 富, 即使在土壤增温后水分有效性也相对较高(特 别是在雨季), 因而土壤增温后细根生产量较高。

由于森林生态系统类型、林龄和系统背景值等 因素不同, 各生态系统细根对氮沉降的响应并不明 确(Li et al., 2015)。Ostertag (2001)采用土钻法对夏 威夷山地以Metrosideros polymorpha为主的林分研 究表明, 当土壤氮添加量增加时, $<2 \mathrm{~mm}$ 细根生产 量下降。Liu和Greaver (2010)针对已发表的110篇文 献进行了一个meta分析, 其中涵盖10种类型的生态 系统, 添加氮肥的范围为10-650 $\mathrm{kg} \cdot \mathrm{hm}^{-2} \cdot \mathrm{a}^{-1}$, 分析 显示氮添加在总体上对细根生产量没有影响, 从不 同生态系统类型来看, 温带针叶林和苔原细根生产
量在氮添加后分别增加了 $9 \%$ 和 $74 \%$ 。本研究中氮添 加对细根生产量没有显著影响可能有两个原因: (1) 该研究区本底土壤氮有效性较高, 且氮添加对土壤 氮有效性的影响比增温小, 因而氮添加对细根生产 没有显著影响; (2)细根生产量受不同的碳分配机制 的共同调控(Chen et al., 2013)。在氮受限制的生态 系统(如温带和苔原生态系统), 氮有效性增加会促 进林木生长, 从而促进细根生产, 以异速生长限制 为主; 而在生长稳定且氮有效性较高的生态系统, 氮有效性增加可能会抑制细根生产, 以木质生产和 细根生产权衡为主(Chen et al., 2013)。本研究中杉 木幼苗处于个体快速生长之中, 可能受到异速生长 限制、木质生产和细根生产权衡的共同限制, 导致 细根生产对氮添加的响应不显著。

\section{3 细根生产量的径级分布}

0-1 mm细根是吸收水分和养分的主要器官, 相 对于 1-2 mm细根更为活跃和敏感, 各处理的 0-1 $\mathrm{mm}$ 细根生产量占细根总生产量的比重均超过 $90 \%$ 。 黄锦学等(2012)对细柄阿丁枫(Altingia grlilipes)和 米槠(Castanopsis carlesii)天然林细根分布的研究 也发现0-1 mm细根占0-2 mm细根总生产力的比重 达到 $90 \%$ 以, 表明 $0-1 \mathrm{~mm}$ 细根对细根生产的贡献 更为重要。本研究中, 土壤增温和径级的交互作用 对细根生产量有显著影响, 土壤增温只对 $0-1 \mathrm{~mm}$ 径 级的细根生产量有显著的促进作用, 这表明小径级 的吸收根对于增温的响应更具有可塑性, 也体现了 增温增强了杉木幼苗的养分获取能力。而氮添加对 两个径级中的细根生产量均没有影响, 这可能是因 为该研究区土壤氮有效性较高, 氮添加对细根生产 的影响较小。

\section{4 细根生产量的季节动态}

本研究发现土壤增温、氮添加及两者的交互作 用对杉木幼苗细根生产的影响因季节而异。在春季, 土壤增温后幼苗细根可能会较早地进入生长季; 春 季亦是细根生产的高峰, 需要大量的土壤养分, 而 
增温后养分矿化速率增加; 同时春季的土壤含水量 高, 增温后细根生产不大可能受土壤水分限制, 这 些因素综合作用使增温以及增温和氮添加的交互作 用对春季细根生产有显著的促进作用 (Majdi \& Öhrvik, 2004)。在夏季, 土壤温度较高, 而增温后土 壤温度更高, 土壤含水率亦降低, 细根生长容易受 到高温和干旱限制, 因而增温对细根生产有显著的 抑制作用。Bai等(2010)也指出在水分受限制的生态 系统如温带半干旱草原, 细根生长对水分有效性非 常敏感, 增温会显著降低细根生产量。而氮添加可 能进一步加剧了杉木幼苗的生理干旱, 从而导致土 壤增温和氮添加对细根生产的影响存在显著的交互 作用。在秋季和冬季, 土壤增温、氮添加以及两者 的交互作用对细根生产均没有显著影响, 这可能与 这些季节幼苗对土壤养分、水分需求量较低, 细根 生产量较低, 因此细根生产对土壤环境变化的敏感 性较低有关。

\section{5 细根生产量的垂直分布}

土壤增温、土层以及土壤增温和土层的交互作 用对细根生产有显著影响, 表明土壤增温对细根的 垂直分布有显著的作用, 而氮添加对细根的垂直分 布没有影响。不同处理的细根峰值有不同的分布模 式: 不增温处理细根生产峰值均出现在10-20 cm 土层; 而增温处理中, W 和WHN处理细根生产峰值 出现在20-30 cm土层, WLN处理细根生产峰值出现 在30-40 cm土层, 表明增温对较深层土壤中的细根 生产有促进作用。Leppälammi-Kujansuu等 (2013) 对挪威云杉的试验也表明, 增温使较深层土壤中的 细根生物量增加; Johnson等(2006)对花旗松 (Pseudotsuga menziesii)的研究表明增温会使细根向更深 层土壤分布。这与Wu等(2014)发现增温会使高山草 甸的细根有向0-10 cm表土层分布的趋势不同。

进一步分析发现, 仅在20-30 cm土层, 土壤增 温对细根生产量有显著的促进作用。其可能原因是: 土壤增温电缆布设在土壤 $10 \mathrm{~cm}$ 处, 土壤表层的增 温幅度最大, 土壤水分蒸发较快, 土壤含水量降低 最多, 因而增温对表层土壤 $(0-10 \mathrm{~cm}, 10-20 \mathrm{~cm})$ 细 根生产没有促进作用; 相反, 较深土层(20-30 cm) 土壤含水量较高, 细根生产受水分限制小, 增温促 进细根生产。但在更深土层(30-40 cm)没有发现增 温对细根生产的促进作用, 这可能与该土层土壤增 温幅度较低有关(章宪等, 2014)。

\section{4 结论}

(1)土壤增温对细根生产量有显著的促进作用, 土壤增温可能通过提高养分有效性使细根生产量增 加。(2)土壤增温和径级的交互作用对细根生产量有 显著影响, 土壤增温显著增加了 0-1 mm径级的细根 生产量。(3)土壤增温、季节、土壤增温和季节的交 互作用, 以及土壤增温、氮添加和季节三者的交互 作用对细根生产量均有显著影响。特别是春季增温 后养分矿化速率增加, 且春季的土壤含水量高, 这 些因素的综合作用使增温以及增温和氮添加的交互 作用对春季细根生产有显著的促进作用; 在夏季, 由于土壤增温与环境高温的叠加作用以及氮添加可 能进一步加剧杉木幼苗的生理干旱, 导致土壤增 温、氮添加以及两者的交互作用对细根生产量有显 著的抑制作用。(4)土壤增温仅对20-30 cm土层的细 根生产有显著的促进作用, 表明土壤增温促使细根 向更深层土壤分布。研究表明, 土壤增温促进了杉 木幼苗细根生产，但其影响因径级、季节和土层而 异; 氮添加对细根生产没有影响; 土壤增温和氮添 加仅在春季和夏季才存在显著的交互作用。但是本 文仅以细根出生数量作为生产量的指标, 而没有考 虑细根长度、体积等形态指标, 也没有对细根生产 量进行转换, 对估计细根的生产量有一定的难度。

基金项目 国家自然科学基金(31422012)、国家重 点基础研究发展计划(973计划)(2014CB460602)、福 建省杰出青年基金(2014J07005)。

致谢 感谢福建三明森林生态系统与全球变化研究 站刘小飞、陈仕东、林伟盛、胥超老师在野外工作 中给予的帮助。

\section{参考文献}

Bai WM, Wan SQ, Niu SL, Liu WX, Chen QS, Wang QB, Zhang WH, Han XG, Li LH (2010). Increased temperature and precipitation interact to affect root production, mortality, and turnover in a temperate steppe: Implications for ecosystem C cycling. Global Change Biology, 16, 1306-1316.

Chen GS, Yang YS, Robinson D (2013). Allocation of gross primary production in forest ecosystems: Allometric constraints and environmental responses. New Phytologist, 200, 1176-1186.

Chen SD, Liu XF, Xiong DC, Lin WS, Lin CF, Xie L, Yang YS (2013). A preliminary study on effects of continuous active warming on soil respiration rates in central sub-tropical forests. Journal of Subtropical Resources and 
Environment, 4, 1-8. (in Chinese with English abstract) [陈仕东, 刘小飞, 熊德成, 林伟盛, 林成芳, 谢麟, 杨 玉盛 (2013). 持续性主动增温对中亚热带森林土壤呼 吸影响研究初报. 亚热带资源与环境学报, 4, 1-8.]

Davidson EA (2009). The contribution of manure and fertilizer nitrogen to atmospheric nitrous oxide since 1860. Nature Geoscience, 2, 659-662.

Fitter AH, Self GK, Brown TK, Bogie DS, Graves JD, Benham D, Ineson P (1999). Root production and turnover in an upland grassland subjected to artificial soil warming respond to radiation flux and nutrients, not temperature. Oecologia, 120, 575-581.

Hendricks JJ, Nadelhoffer KJ, Aber JD (1993). Assessing the role of fine roots in carbon and nutrient cycling. Trends in Ecology \& Evolution, 8(5), 174-178.

Huang JX, Chen GS, Yang ZJ, Xiong DC, Guo JF, Xie JS, Robinson D, Yang YS (2016). Understory fine roots are more ephemeral than those of trees in subtropical Chinese fir (Cunninghamia lanceolata (Lamb.) Hook) stands. Annals of Forest Science, 73, 657-667.

Huang JX, Ling H, Yang ZJ, Lu ZL, Xiong DC, Chen GS, Yang YS, Xie JS (2012). Estimating fine root production and mortality in subtropical Altingia grlilipes and Castanopsis carlesii forests. Acta Ecologica Sinica, 32, 4472-4480. (in Chinese with English abstract) [黄锦学, 凌华, 杨智杰, 卢正立, 熊德成, 陈光水, 杨玉盛, 谢锦升 (2012). 中 亚热带细柄阿丁枫和米槠群落细根的生产和死亡动态. 生态学报, 32, 4472-4480.]

IPCC (Intergovernmental Panel on Climate Change) (2013). Contribution of working group 1 to the fifth assessment report of the intergovernmental panel on climate change. In: Stocker TF, Qin DH, Plattner GK, Tignor M, Allen SK, Boschung J, Nauels A, Xia Y, Bex V, Midgley PM eds. Climate Change in 2013: The Physical Science Basis. Cambridge University Press, Cambridge, UK.

Johnson MG, Rygiewicz PT, Tingey DT, Phillips DL (2006). Elevated $\mathrm{CO}_{2}$ and elevated temperature have no effect on Douglas-fir fine-root dynamics in nitrogen-poor soil. New Phytologist, 170, 345-356.

Lamarque JF, Kiehl JT, Brasseur GP, Butler T, Cameron-Smith P, Collins WD, Collins WJ, Granier C, Hauglustaine D, Hess PG, Holland EA, Horowitz L, Lawrence MG, McKenna D, Merilees P, Prather MJ, Rasch PJ, Rotman D, Shindell D, Thornton P (2005). Assessing future nitrogen deposition and carbon cycle feedback using a multimodel approach: Analysis of nitrogen deposition. Journal of Geophysical Research Atmospheres, 110(D19), 2657-2677.

Leppälammi-Kujansuu J, Ostonen I, Strömgren M, Nilsson LO, Kleja DB, Sah SP, Helmisaari HS (2013). Effects of long-term temperature and nutrient manipulation on Norway spruce fine roots and mycelia production. Plant and Soil, 366, 287-303.

Leppälammi-Kujansuu J, Salemaa M, Kleja DB, Linder S,
Helmisaari HS (2014). Fine root turnover and litter production of Norway spruce in a long-term temperature and nutrient manipulation experiment. Plant and Soil, 374, 73-88.

Li WB, Jin CJ, Guan DX, Wang QK, Wang AZ, Yuan FH, Wu JB (2015). The effects of simulated nitrogen deposition on plant root traits: A meta-analysis. Soil Biology \& Biochemistry, 82, 112-118.

Liu LL, Greaver TL (2010). A global perspective on belowground carbon dynamics under nitrogen enrichment. Ecology Letters, 13, 819-828.

Liu XJ, Duan L, Mo JM, Du EZ, Shen JL, Lu XK, Zhang Y, Zhou XB, He CE, Zhang FS (2011). Nitrogen deposition and its ecological impact in China: An overview. Environmental Pollution, 159, 2251-2264.

Majdi H, Öhrvik J (2004). Interactive effects of soil warming and fertilization on root production, mortality, and longevity in a Norway spruce stand in Northern Sweden. Global Change Biology, 10, 182-188.

Nadelhoffer KJ (2000). The potential effects of nitrogen deposition on fine-root production in forest ecosystems. New Phytologist, 147, 131-139.

Ostertag R (2001). Effects of nitrogen and phosphorus availability on fine-root dynamics in Hawaiian montane forests. Ecology, 82, 485-499.

State Forestry Administration of the People's Republic of China (2005). The National Forest Resources Statistics (1999-2003). China Forestry Publishing House, Beijing. (in Chinese) [中华人民共和国国家林业局 (2005). 全国 森林资源统计(1999-2003). 中国林业出版社, 北京.]

Wan SQ, Hui DF, Wallace L, Luo YQ (2005). Direct and indirect effects of experimental warming on ecosystem carbon processes in a tallgrass prairie. Global Biogeochemical Cycles, 19, GB2014, doi:10.1029/2004GB002315.

Wan SQ, Norby RJ, Pregitzer KS, Ledford J, O’Neill EG (2004). $\mathrm{CO}_{2}$ enrichment and warming of the atmosphere enhance both productivity and mortality of maple tree fine roots. New Phytologist, 162, 437-446.

Way DA, Oren R (2010). Differential responses to changes in growth temperature between trees from different functional groups and biomes: A review and synthesis of data. Tree Physiology, 30, 669-688.

Wu YB, Zhang J, Deng YC, Wu J, Wang SP, Tang YH, Cui XY (2014). Effects of warming on root diameter, distribution, and longevity in an alpine meadow. Plant Ecology, 215, 1057-1066.

Zhang X, Liu XF, Chen SD, Xiong DC, Lin WS, Lin TW, Lin CF (2014). Effects of soil warming on the temperature of soil in different depths. Journal of Subtropical Resources and Environment, 9, 89-91. (in Chinese with English abstract) [章宪, 刘小飞, 陈仕东, 熊德成, 林伟盛, 林廷 武, 林成芳 (2014). 土壤增温对不同深度土壤温度的影 响. 亚热带资源与环境学报, 9, 89-91.]

特邀编委: 陈 槐 责任编辑: 王 蒇 

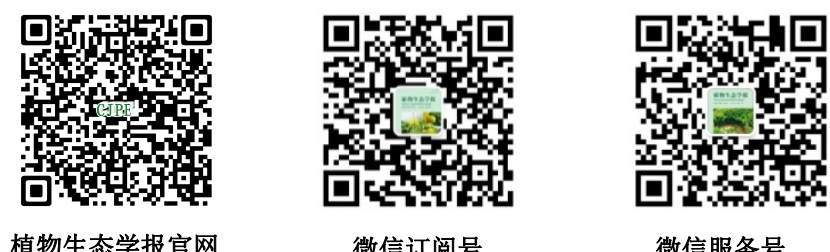

植物生态学报官网

微信服务号

期刊及学科

稿件状态查询

相关信息发布

全文检索浏览 